\title{
Article \\ Cellular and Molecular Targets of Nucleotide-Tagged Trithiolato-Bridged Arene Ruthenium Complexes in the Protozoan Parasites Toxoplasma gondii and Trypanosoma brucei
}

\author{
Nicoleta Anghel ${ }^{1, \dagger}{ }^{\dagger}$, Joachim Müller ${ }^{1, *}+\oplus$, Mauro Serricchio ${ }^{2} \oplus$, Jennifer Jelk ${ }^{2}$, Peter Bütikofer ${ }^{2}$, \\ Ghalia Boubaker ${ }^{1}$, Dennis Imhof ${ }^{1}$, Jessica Ramseier ${ }^{1}$, Oksana Desiatkina ${ }^{3}$, Emilia Păunescu ${ }^{3}$, \\ Sophie Braga-Lagache ${ }^{4}$, Manfred Heller ${ }^{4}\left(\mathbb{D}\right.$, Julien Furrer ${ }^{3}$ and Andrew Hemphill ${ }^{1, *} \mathbb{E}$
}

check for updates

Citation: Anghel, N.; Müller, J.; Serricchio, M.; Jelk, J.; Bütikofer, P.; Boubaker, G.; Imhof, D.; Ramseier, J.; Desiatkina, O.; Păunescu, E.; et al. Cellular and Molecular Targets of Nucleotide-Tagged

Trithiolato-Bridged Arene Ruthenium Complexes in the Protozoan Parasites Toxoplasma gondii and Trypanosoma brucei. Int. J. Mol. Sci. 2021, 22, 10787. https://doi.org/10.3390/ijms221910787

Academic Editors: Antonello Merlino and Giarita Ferraro

Received: 10 September 2021

Accepted: 2 October 2021

Published: 5 October 2021

Publisher's Note: MDPI stays neutral with regard to jurisdictional claims in published maps and institutional affiliations.

Copyright: () 2021 by the authors. Licensee MDPI, Basel, Switzerland. This article is an open access article distributed under the terms and conditions of the Creative Commons Attribution (CC BY) license (https:// creativecommons.org/licenses/by/ $4.0 /)$.
1 Institute of Parasitology, Vetsuisse Faculty, University of Bern, 3012 Bern, Switzerland; nicoleta.anghel@vetsuisse.unibe.ch (N.A.); ghalia.boubaker@vetsuisse.unibe.ch (G.B.); dennis.imhof@vetsuisse.unibe.ch (D.I.); jessi95@gawnet.ch (J.R.)

2 Institute of Biochemistry and Molecular Medicine, University of Bern, 3012 Bern, Switzerland; mauro.serricchio@ibmm.unibe.ch (M.S.); jennifer.jelk@ibmm.unibe.ch (J.J.); peter.buetikofer@ibmm.unibe.ch (P.B.)

3 Department of Chemistry, Biochemistry and Pharmaceutical Sciences, University of Bern, 3012 Bern, Switzerland; oksana.desiatkina@unibe.ch (O.D.); paunescu_emilia@yahoo.com (E.P.); julien.furrer@unibe.ch (J.F.)

4 Proteomics and Mass Spectrometry Core Facility, Department for BioMedical Research (DBMR), University of Bern, 3012 Bern, Switzerland; sophie.lagache@dbmr.unibe.ch (S.B.-L.); manfred.heller@dbmr.unibe.ch (M.H.)

* Correspondence: joachim.mueller@vetsuisse.unibe.ch (J.M.); andrew.hemphill@vetsuisse.unibe.ch (A.H.)

+ These authors contributed equally to the work.

Abstract: Toxoplasma gondii is an apicomplexan parasite that infects and proliferates within many different types of host cells and infects virtually all warm-blooded animals and humans. Trypanosoma brucei is an extracellular kinetoplastid that causes human African trypanosomiasis and Nagana disease in cattle, primarily in rural sub-Saharan Africa. Current treatments against both parasites have limitations, e.g., suboptimal efficacy and adverse side effects. Here, we investigate the potential cellular and molecular targets of a trithiolato-bridged arene ruthenium complex conjugated to 9-(2-hydroxyethyl)-adenine (1), which inhibits both parasites with $\mathrm{IC}_{50} \mathrm{~s}$ below $10^{-7} \mathrm{M}$. Proteins that bind to $\mathbf{1}$ were identified using differential affinity chromatography (DAC) followed by shotgun-mass spectrometry. A trithiolato-bridged ruthenium complex decorated with hypoxanthine (2) and 2-hydroxyethyl-adenine (3) were included as controls. Transmission electron microscopy (TEM) revealed distinct ultrastructural modifications in the mitochondrion induced by (1) but not by (2) and (3) in both species. DAC revealed 128 proteins in T. gondii and 46 proteins in T. brucei specifically binding to $\mathbf{1}$ but not $\mathbf{2}$ or $\mathbf{3}$. In T. gondii, the most abundant was a protein with unknown function annotated as YOU2. This protein is a homolog to the human mitochondrial inner membrane translocase subunit Tim10. In T. brucei, the most abundant proteins binding specifically to $\mathbf{1}$ were mitochondrial ATP-synthase subunits. Exposure of T. brucei bloodstream forms to 1 resulted in rapid breakdown of the ATP-synthase complex. Moreover, both datasets contained proteins involved in key steps of metabolism and nucleic acid binding proteins.

Keywords: mitochondrion; affinity chromatography; binding proteins; ATP-synthase; proteomics; metabolism

\section{Introduction}

Toxoplasma gondii and Trypanosoma brucei belong to two evolutionary distant eukaryotic phyla, namely the clade Alveolata of the super-group Diaphoretickes in the case of T. gondii, and the group Euglenozoa of super-group Excavata in the case of T. brucei [1]. T. gondii 
causes important diseases in farm animals, has an enormous global economic impact, and has a high zoonotic potential [2]. In immunocompetent hosts, infection does not have serious consequences, and the proliferative tachyzoite form differentiates into the tissue cyst-forming bradyzoite stage, which can persist over many years to lifelong without causing any clinical symptoms. However, Toxoplasma is a major abortion-causing pathogen in sheep and other farm animals, and primary infection in pregnant women with T. gondii can lead to vertical transmission, causing fetal malformations and/or abortion [3]. In patients undergoing immunosuppressive disease or therapy, reactivation of bradyzoites from tissue cysts and re-differentiation into tachyzoites often causes serious pathology. Current drug treatments for toxoplasmosis therapy typically include antifolates using a combination of pyrimethamine-sulfadiazine or trimethoprim-sulfamethoxazole, and pyrimethamine can also be combined with clindamycin, azithromycin, or atovaquone. These treatments are unspecific, adverse effects have been frequently documented, and clinical failures have been reported [4]. While toxoplasmosis is a food-borne disease, human African trypanosomiasis (HAT) is a vector-borne disease, and transmission of T. brucei gambiense and T. b. rhodesiense to humans occurs via the tsetse fly [5]. Another T. brucei subspecies, T. b. brucei, is one of the causative agents of a wasting disease in cattle, called Nagana, which inflicts high economic and social impact in African rural areas [6]. Treatment options of HAT include pentamidine and suramin for the early and peripheral stage of the disease, and melarsoprol and eflornithine alone or in combination with nifurtimox for the cerebral phase [7]. More recently, 2-5-nitroimidazole fexinidazole has been approved for human use (https: / / dndi.org/research-development/portfolio/fexinidazole/; accessed on 15 June 2021). Veterinary trypanocides to treat Nagana include diminazene aceturate and isometam, and they are prone to drug resistance development.

T. gondii and T. brucei occupy two different ecological niches. T. gondii is an intracellular parasite that resides and proliferates within a parasitophorous vacuole that is located within the cytoplasm of a host cell [8,9]. In contrast, T. brucei is an extracellular parasite, with the mammalian bloodstream forms undergoing antigenic variation and surviving in the blood and lymphatic vessels prior to crossing the blood-brain barrier, where they also remain in the extracellular space $[10,11]$. A common feature of both species is the presence of a single mitochondrion, which adopts a tube-like structure. The T. gondii mitochondrion typically exhibits an electron-dense matrix with clearly visible cristae structures, and components of the electron transport chain mediating oxidative phosphorylation are being regarded as highly valuable drug targets. In T. brucei bloodstream forms, the mitochondrion is largely devoid of discernible cristae, and the mitochondrial DNA is organized into a condensed structure named kinetoplast that is localized in a dilated area and is physically associated with the flagellar base and the flagellar pocket. Although the respiratory chain is not functional in T. brucei bloodstream forms, the mitochondrion is essential for parasite survival. Thus, compounds targeting mitochondrial function and structural integrity represent attractive drug candidates for the treatment of both parasitic infections.

In the last decade, extensive research has been carried out to identify suitable molecular drug targets in protozoan parasites that cause diseases in animals and humans [12,13]. Previously published in vitro studies have revealed that trithiolato-bridged dinuclear ruthenium(II)-arene complexes were effective against T. gondii [14-17], Neospora caninum $[17,18]$, and T. brucei [19]. To improve the effectivity of these ruthenium complexes, their organic substituents have attracted special attention [20]. Since many parasites lack de novo synthesis pathways of essential metabolites and have therefore become auxotrophic [21], it is tempting to conjugate $\mathrm{Ru}(\mathrm{II})$ complexes with such metabolites. As these parasites need to scavenge essential components from their hosts, this could improve their uptake and binding to specific targets [22]. Trying to exploit purine auxotrophy [23], we have designed various conjugates based on a trithiolato-bridged dinuclear ruthenium(II)-arene scaffold with anchored purines or purine analogues [Desiatkina et al., 2021, manuscript in preparation]. 
In this study, we investigated the activity of compound 1, which was identified in the screening for anti-T. gondii activity, containing a 9-(2-hydroxyethyl)-adenine group, against $T$. brucei. Compound 2, a structurally related complex with 2-thioxanthine as one of the bridge thiols, and compound 3 (with 9-(2-hydroxyethyl)-adenine as one of the bridge thiols) were also assessed for comparison. Compounds 1-3 are shown in Figure 1. We also investigated whether common (sub-)cellular and/or molecular targets exist in these evolutionary and ecologically distant protozoan parasites using electron microscopy of cells treated with all three compounds. Previous studies on pull-downs with a trithiolato-bridged arene $\mathrm{Ru}(\mathrm{II})$ complex decorated with different substituents have suggested nucleic acid binding proteins, in particular elongation factor $1 \alpha$ and ribosomal proteins, as potential binding proteins [14]. However, the identification of these proteins was based on in-gel-digestion of protein bands after SDS-PAGE and was therefore biased.

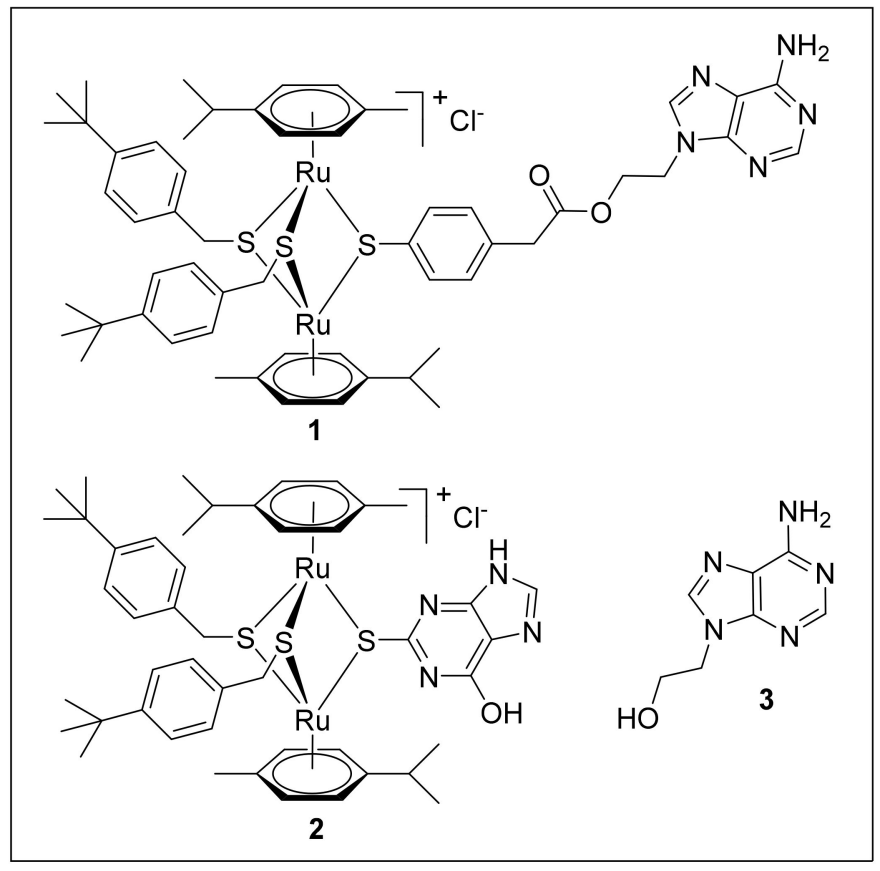

Figure 1. Structure of compounds $\mathbf{1}-\mathbf{3}$ used in this study. $\mathbf{1}$ is a trithiolato-bridged dinuclear $\mathrm{Ru}(\mathrm{II})$ -arene conjugate containing a 9-(2-oxyethyl)-adenine unit, 2 is a trithiolato-bridged dinuclear $\mathrm{Ru}(\mathrm{II})$ arene complex with 2-thioxanthine as one of the bridge thiols, and 3 is 9-(2-hydroxyethyl) -adenine.

\section{Results}

\subsection{Compound 1 Inhibits Parasite Proliferation and Targets the Parasite Mitochondrion}

Drug effects against $\mathrm{T}$. gondii tachyzoites were assessed in vitro using a transgenic T. gondii strain grown in human foreskin fibroblast (HFF) monolayers that constitutively expresses $\beta$-galactosidase. Effects on T. brucei viability were determined by AlamarBlue ${ }^{\circledR a s s a y . ~ C o m p o u n d ~} 1$ inhibited the proliferation of $\mathrm{T}$. gondii tachyzoites with an $\mathrm{IC}_{50}$ of $59 \mathrm{nM}$. but neither 2-thioxanthine compound 2 nor adenine derivative (3) exhibited notable activities (see Table 1; (Desiatkina et al., 2021, manuscript in preparation). Similar results were obtained with $T$. brucei bloodstream forms where $\mathbf{1}$ severely impaired parasite viability $\left(\mathrm{IC}_{50}=29 \mathrm{nM}\right)$, while the other two compounds remained largely ineffective. None of the compounds had any effect on HFF viability or morphology at a concentration of $2.5 \mu \mathrm{M}$ (Desiatkina et al., 2021, manuscript in preparation). 
Table 1. $\mathrm{IC}_{50}$ values of the three compounds used in this study.

\begin{tabular}{cccc}
\hline Compound & MW & IC $_{50}$ T. gondii $(\mathbf{n M}) *$ & IC $_{50}$ T. brucei $(\mathbf{n M})$ \\
\hline $\mathbf{1}$ & 1193 & 59 & 29 \\
$\mathbf{2}$ & 1032 & $>1000$ & $>1000$ \\
$\mathbf{3}$ & 179 & $>1000$ & $>1000$ \\
\hline
\end{tabular}

*values presented in Desiatkina et al., 2021, manuscript in preparation.

Transmission electron microscopy (TEM) was performed to study the ultrastructural alteration during these treatments. Results for tachyzoites of the T. gondii Me49 strain are shown in Figures 2 and 3. In non-treated control cultures (Figure 2A,B), tachyzoites were found within the cytoplasm of host cells, where they formed a parasitophorous vacuole that was delineated by a parasitophorous vacuole membrane. The apical complex with the conoid, and secretory organelles such as micronemes (mic), rhoptries (rop), and dense granules $(\mathrm{dg})$ were clearly discernible. Tachyzoites harbor a single mitochondrion that displays an electron-dense and highly structured matrix, of which one or more portions are readily visible, depending on the section plane (Figure 2B). Upon treatment of cultures with $500 \mathrm{nM}$ of 1 , the most notable changes occurred already after $6 \mathrm{~h}$ in the mitochondrial matrix, resulting in a complete disappearance of cristae and associated structures. However, the overall shape and structure as well as the secretory organelles of the parasites remained unaffected. In addition, the structural integrity of the parasitophorous vacuole was maintained, even after $12 \mathrm{~h}$ (Figure 3A) and $24 \mathrm{~h}$ of treatment (Figure 3B-D), with alterations in the mitochondria still evident. Occasionally, lipid droplets could be detected in the cytoplasm of treated parasites (Figure 3A). In some instances, tachyzoites appeared to be embedded in the matrix of the parasitophorous vacuole that had a rather solid structure; in other cases, the matrix appeared as a more loose and less electron-dense structural entity. No structural changes were evident upon treatment of $T$. gondii tachyzoites grown in host cells in the presence of $\mathbf{2}$ and $\mathbf{3}$ (data not shown).

TEM micrographs of T. brucei TREU927 bloodstream forms are shown in Figure 4. No structural differences were evident between non-treated bloodstream forms and trypanosomes treated with 2 or $\mathbf{3}$. Parasites displayed the typical hallmarks of trypanosomatids. These include the flagellum (f) with an axoneme and the paraflagellar rod, which emerges from the posterior end and then runs along the entire body toward the anterior part of the cell. In addition, portions of the mitochondrion (mito) were visible, depending on the section plane, surrounded by a double membrane and filled with a fine, slightly electron-dense matrix.

Cristae or cristae-like structures were occasionally protruding from the inner membrane into the mitochondrial matrix (Figure 4A-D). The membrane stacks of the Golgi apparatus appeared normal (Figure $4 \mathrm{D}$, and the kinetoplast $(\mathrm{k})$, located at the posterior end, and also integrated into the mitochondrion, was identifiable as a highly ordered entity (Figure 4E).

In contrast, T. brucei bloodstream forms treated with $200 \mathrm{nM}$ of $\mathbf{1}$ for $4 \mathrm{~h}$ showed distinct early ultrastructural alterations, most notably in the mitochondrion (Figure 5). Compound $\mathbf{1}$ induced swelling of the mitochondrion. The matrix appeared less electrondense compared to the controls and was devoid of cristae-like membranous protrusions but often contained non-defined filamentous or membranous components. In many instances, the kinetoplast had lost its characteristic overall electron-dense appearance and was fragmented (Figure 5B,C). In addition, in some instances, parasites were observed that had undergone partial leakage of cytoplasmic content, which was reflected by a lower electron density of the cytoplasm, and a deterioration of structural organization of the cells, as seen by the presence of flagellar structures within the cytoplasm (Figure 5F). 


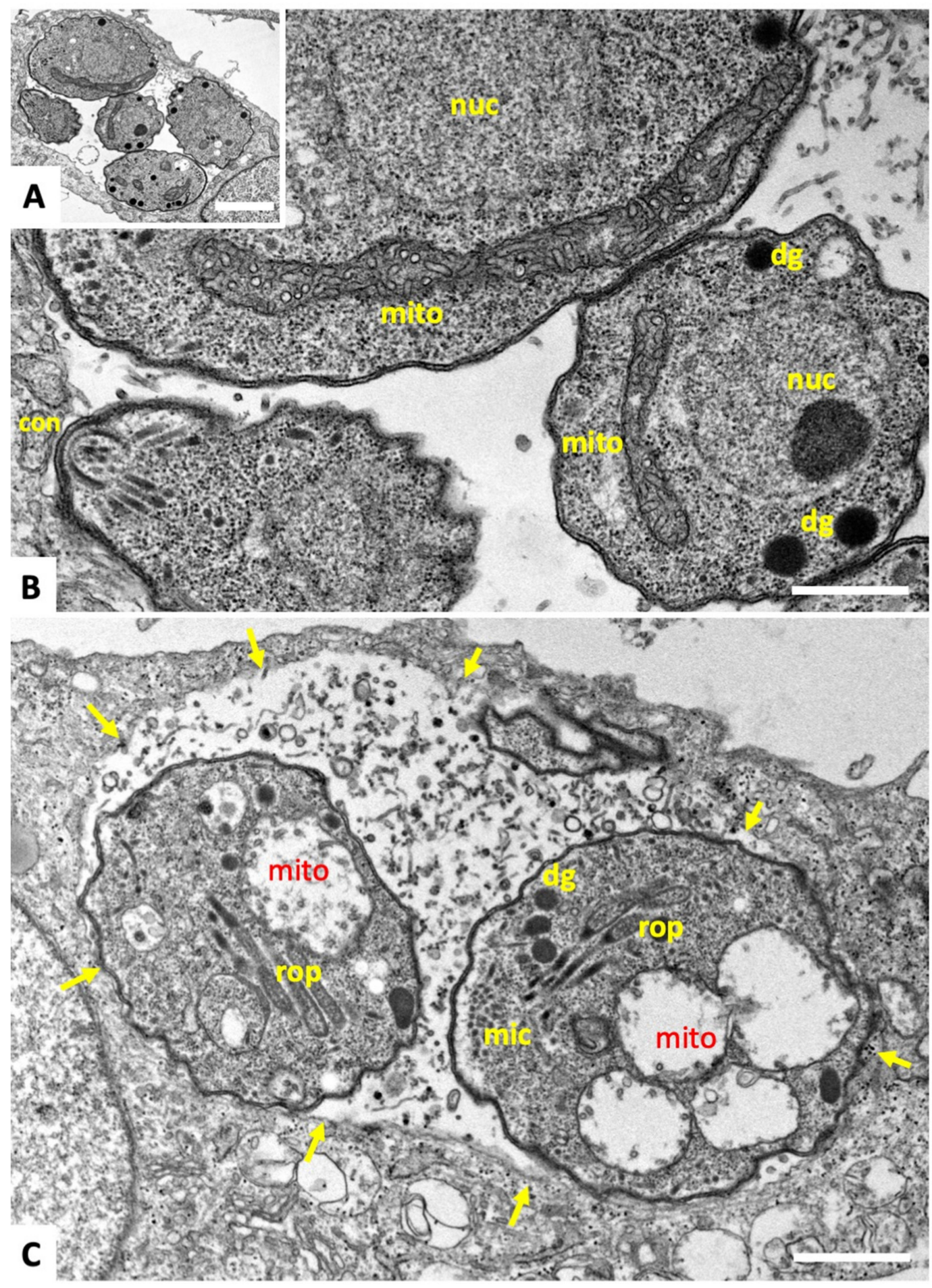

Figure 2. TEM of T. gondii tachyzoites grown in human foreskin fibroblasts. (A,B) are non-treated tachyzoites, (C) shows tachyzoites treated with $500 \mathrm{nM}$ of compound $\mathbf{1}$ for $6 \mathrm{~h}$. B is a higher magnification view of $\mathbf{A}$. The arrows delineate the membrane of the parasitophorous vacuole; $n u c=$ nucleus, rop $=$ rhoptries, $\mathrm{dg}=$ dense granules, mic $=$ micronemes, mito $=$ mitochondrion, con = conoid. Bar in $\mathbf{A}=1.0 \mu \mathrm{m}$; in $\mathbf{B}$ and $\mathbf{C}=0.3 \mu \mathrm{m}$. 


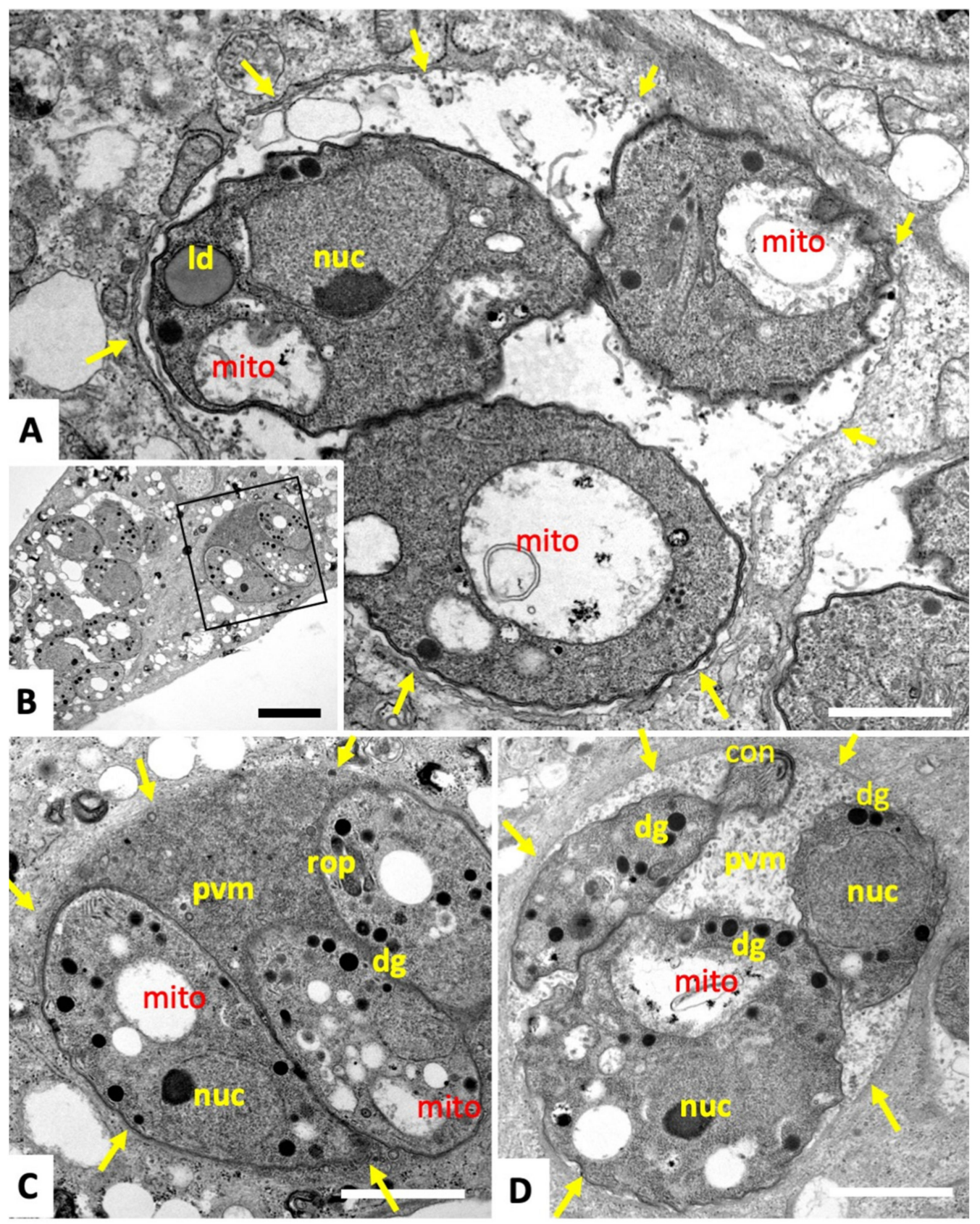

Figure 3. TEM of T. gondii tachyzoites grown in human foreskin fibroblasts and treated with $500 \mathrm{nM}$ of compound 1. Panel (A) shows parasites treated for $6 \mathrm{~h}$, exhibiting a profoundly altered mitochondrion. (B,C) show infected cultures treated for $12 \mathrm{~h}$, with $\mathrm{C}$ being a higher magnification view of the boxed area in B. (D) shows a culture maintained in the presence of 1 for $24 \mathrm{~h}$. The arrows delineate the membrane of the parasitophorous vacuole; $l d=$ lipid droplet, nuc $=$ nucleus, rop = rhoptries, $\mathrm{dg}=$ dense granules, $\mathrm{mic}=$ micronemes, mito $=$ mitochondrion, con $=$ conoid, pvm $=$ parasitophorous vacuole matrix. Bar in $\mathbf{A}=0.5 \mu \mathrm{m}$; in $\mathbf{B}=2.2 \mu \mathrm{m}$; in $\mathbf{C}$ and $\mathbf{D}=1.1 \mu \mathrm{m}$. 


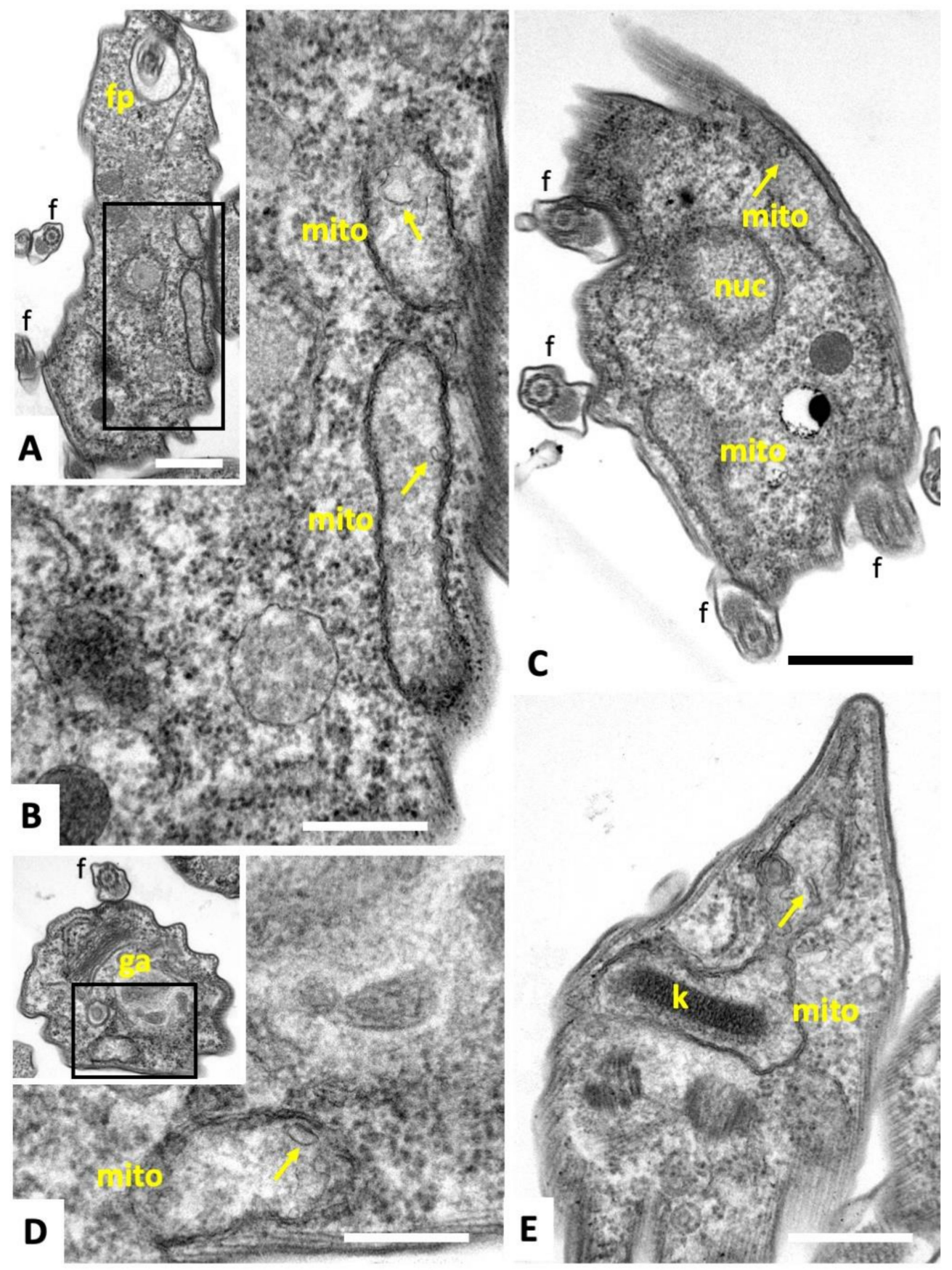

Figure 4. TEM of T. brucei bloodstream forms. (A,B) shows longitudinal sections through the cytoplasm of a parasite cultured in the absence of compounds, with the boxed area in A magnified in B highlighting parts of the mitochondrion. (C,D) show cross-sections of parasites cultured in the presence of compounds 2 and 3, respectively, both at $200 \mathrm{nM}$ for $4 \mathrm{~h}$. In $\mathbf{D}$, the boxed area in the low magnification view is enlarged. (E) shows a section through the posterior part of a parasite treated with 3 . Note the highly ordered kinteoplast structure $(\mathrm{k})$ and partially exposed mitochondrion (mito) that exhibits a rather amorphous and slightly electron-dense matrix with only few cristae-like structures (arrows); ga = golgi apparatus, $\mathrm{k}=$ kinetoplast, $\mathrm{f}=$ flagellum, $\mathrm{fp}=$ flagellar pocket. Bar in $\mathbf{A}=0.35 \mu \mathrm{m} ;$ in $\mathbf{B}=0.2 \mu \mathrm{m} ;$ in $\mathbf{C}=0.3 \mu \mathrm{m} ;$ in $\mathbf{D}=0.2 \mu \mathrm{m}$; in $\mathbf{E}=0.3 \mu \mathrm{m}$. 


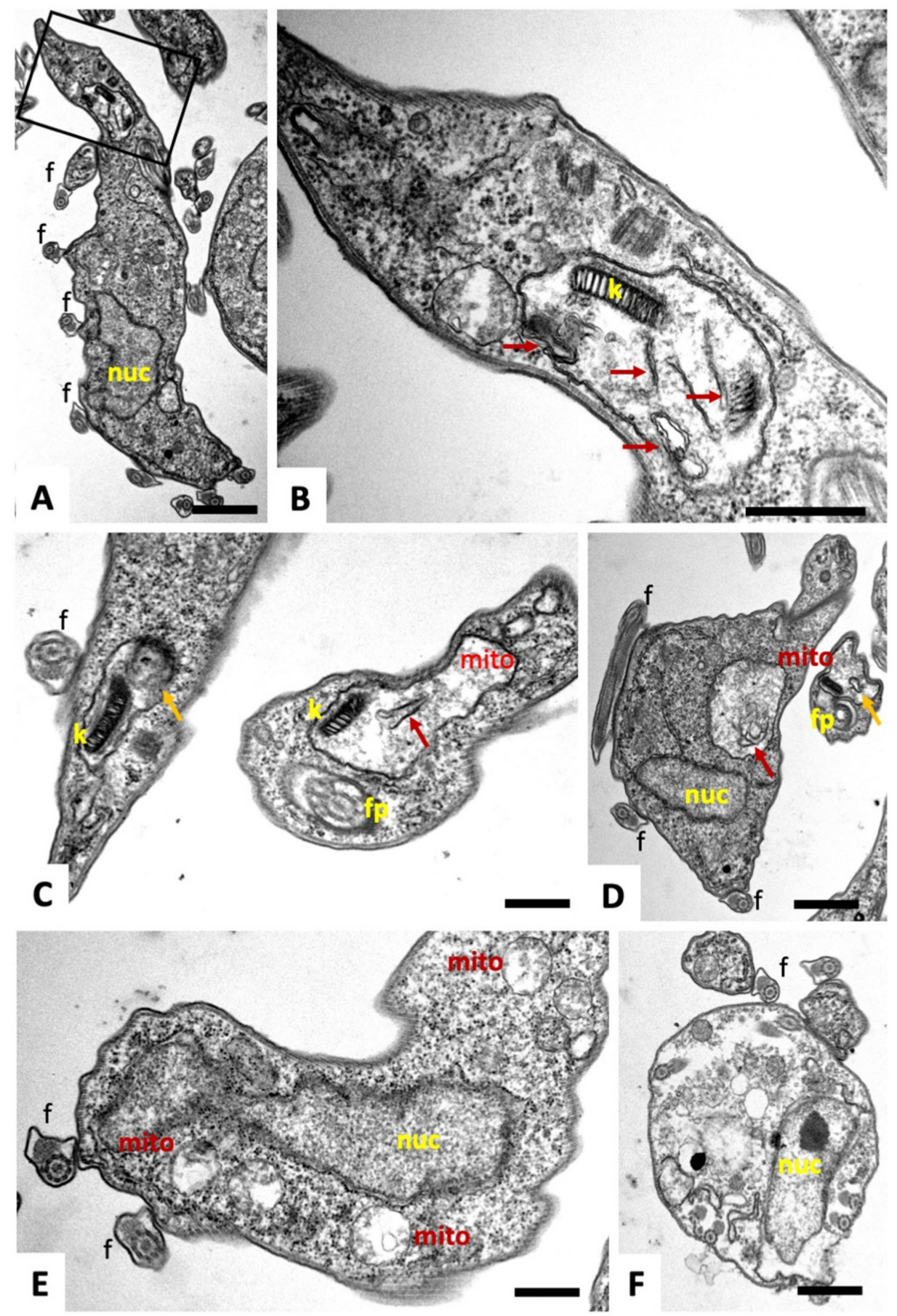

Figure 5. TEM of T. brucei bloodstream forms treated with $200 \mathrm{nM}$ of compound 1 for $4 \mathrm{~h}$. (A) is a lower magnification view of a longitudinal section, the boxed region at the posterior end is magnified in (B). (C) shows two other parasites with altered kinetoplast $(k),(D, E)$ show sections through the mitochondrion in other parts of the cell. Arrows point to the structurally altered mitochondrial matrix, characterized by low electron density and potentially membranous content of unknown nature (red arrows), and membrane fragments (orange arrows). (F) shows parasites with a more severely altered structural organization and apparent loss of cytoplasmic content. mito $=$ mitochondrion, $\mathrm{k}=$ kinetoplast, $\mathrm{f}=\mathrm{flagellum}, \mathrm{fp}=$ flagellar pocket, nuc $=$ nucleus. Bars in $\mathbf{A}=0.8 \mu \mathrm{m}, \mathbf{B}=0.35, \mathbf{C}=0.21 \mu \mathrm{m}, \mathbf{D}=0.4 \mu \mathrm{m}, \mathbf{E}=0.21 \mu \mathrm{m}, \mathbf{F}=0.35 \mu \mathrm{m}$.

\subsection{Identification of Compound-Binding Proteins in T. gondii and T. brucei}

To identify the molecular targets of these compounds, the pull-down fractions obtained from T. gondii ME49 tachyzoites were identified by differential shotgun mass spectrometry. Overall, 2542 unique peptides matching to 375 proteins were identified (Table S1). In the 
pull-down fractions obtained from T. brucei TREU927 blood stream forms, 975 unique peptides matching to 198 proteins were identified (Table S2). Overall analysis of both datasets by principal component analysis using LFQ protein intensity values revealed that the protein patterns obtained from mock and compound 3-colums clustered together. The protein patterns obtained from $\mathbf{1}$ and $\mathbf{2}$ columns were separated by the first and second principal component from each other and from the 3 and mock columns (Figure 6).

\section{T. gondii}

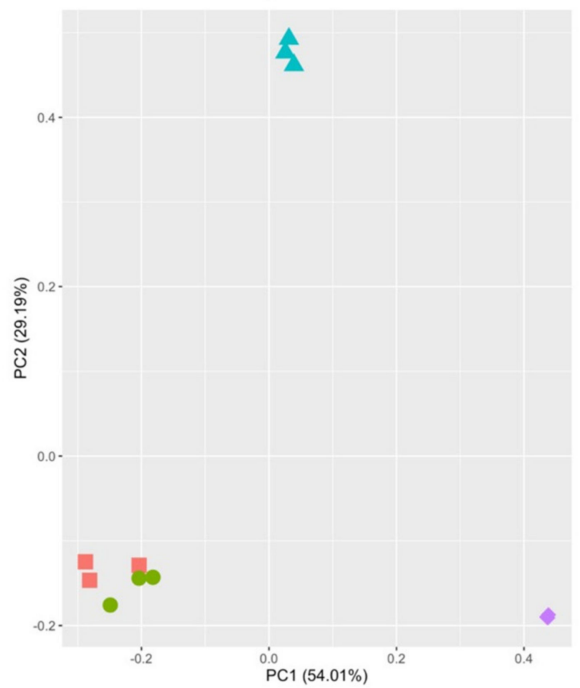

\section{T. brucei}

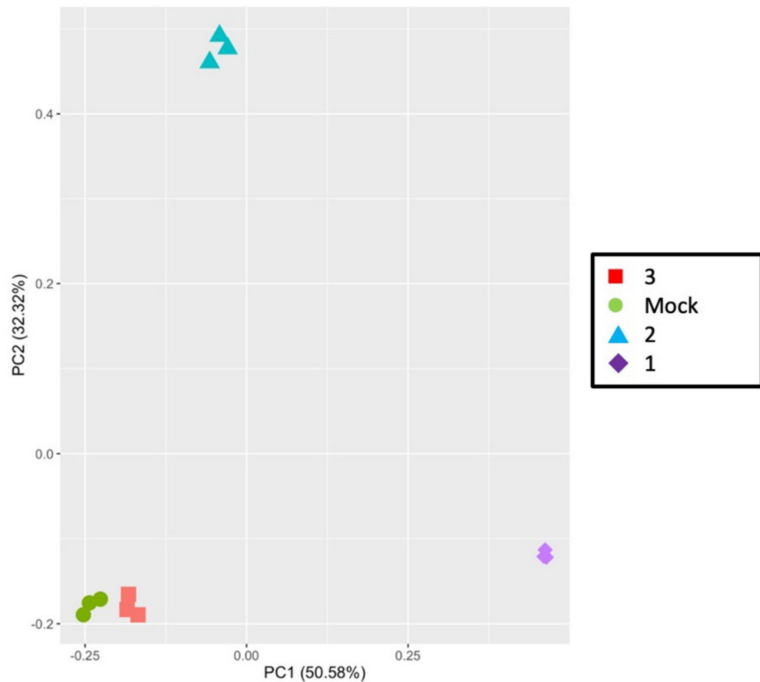

Figure 6. Principal component analysis of proteome dataset from differential pull-downs. Pull-down fractions of cell-free extracts from T. gondii and T. brucei from mock, 3, 2, or $\mathbf{1}$ columns were compared by MS shotgun analysis as described in Materials and Methods. The LFQ values of technical replicates are shown.

A closer look at the T. gondii pulldown revealed that of the 277 proteins that did not bind to the mock column, 122 proteins were specifically retained by compound $\mathbf{1}$. A total of 130 proteins retained by $\mathbf{1}$ were also identified in the column $\mathbf{2}$ and/or $\mathbf{3}$ fractions. In the T. brucei pulldown, 44 of the 94 proteins not retained by the mock column were specifically eluted from the compound $\mathbf{1}$ column, and 34 proteins were also eluted from the other columns (Figure 7).

\section{T. gondii}

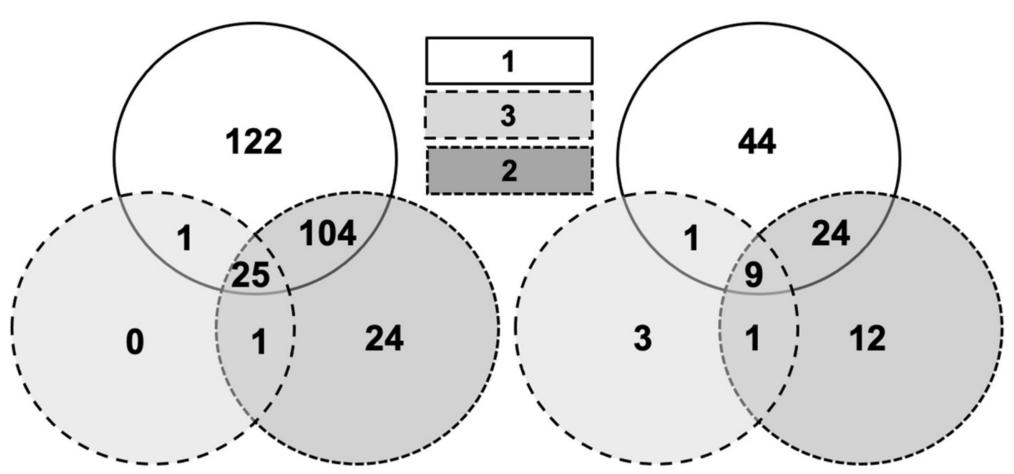

Figure 7. Venn diagram detailing the number of proteins from differential pull-downs. Pull-down fractions of extracts from T. gondii and T. brucei from 1, 2, and 3 columns were compared by MS shotgun analysis as described in Materials and Methods. 


\subsection{The Major Compound 1-Binding Proteins}

Amongst the $122 \mathrm{~T}$. gondii proteins, which were specifically retained by $\mathbf{1}$, the protein encoded by the open reading frame (ORF) TGME49_319730, annotated as a YOU2 family $\mathrm{C} 2 \mathrm{C} 2$ zinc finger protein, was-by far-the most abundant one with ca. $30 \%$ of the binding proteins (Table 2).

Table 2. List of the 20 most abundant proteins from T. gondii ME49 specifically binding to the compound 1 column, as identified by differential affinity chromatography followed by mass spectrometry. See Table S1 for the full dataset. The abundance is given as the percentage of the iBAQ values, with $100 \%$ being the sum of the $\mathrm{BBAQ}$ values of all 122 proteins specifically binding to 1 . Mean values \pm standard errors of three replicates are given.

\begin{tabular}{|c|c|c|}
\hline ORF Number & Annotation & $\begin{array}{c}\text { iBAQ } \\
\text { (\% of Total) }\end{array}$ \\
\hline TGME49_319730 & YOU2 family $\mathrm{C} 2 \mathrm{C} 2$ zinc finger protein & $30.3 \pm 1.5$ \\
\hline TGME49_316710 & Hypothetical protein & $7.1 \pm 1.1$ \\
\hline TGME49_278270 & $\begin{array}{c}\text { Nucleolar protein, structural component of H/ACA snoRNPs, } \\
\text { putative }\end{array}$ & $5.1 \pm 1.0$ \\
\hline TGME49_215350 & Hypothetical protein & $4.6 \pm 0.2$ \\
\hline TGME49_263990 & Hypothetical protein & $4.3 \pm 0.3$ \\
\hline TGME49_214940 & MIC2-associated protein M2AP & $3.8 \pm 0.3$ \\
\hline TGME49_221510 & Hypothetical protein & $2.6 \pm 0.3$ \\
\hline TGME49_236040 & Fructose-1,6-bisphosphate aldolase & $2.5 \pm 0.3$ \\
\hline TGME49_221620 & Beta-tubulin, putative & $1.9 \pm 0.5$ \\
\hline TGME49_264040 & Hypothetical protein & $1.9 \pm 0.1$ \\
\hline TGME49_288245 & Hypothetical protein & $1.8 \pm 0.1$ \\
\hline TGME49_215430 & Hypothetical protein & $1.6 \pm 0.3$ \\
\hline TGME49_294670 & Translation initiation factor 3 subunit & $1.5 \pm 0.1$ \\
\hline TGME49_226410 & EF-1 guanine nucleotide exchange domain-containing protein & $1.3 \pm 0.3$ \\
\hline TGME49_218410 & Ribosomal protein RPP0 & $1.1 \pm 0.2$ \\
\hline TGME49_245620 & Ribosomal-ubiquitin protein RPS27A & $1.0 \pm 0.2$ \\
\hline TGME49_247770 & Hypothetical protein & $0.9 \pm 0.1$ \\
\hline TGME49_289830 & Eukaryotic initiation factor-3, delta subunit, putative & $0.9 \pm 0.1$ \\
\hline TGME49_287210 & Proteasome subunit alpha2, protease of the acylase family & $0.8 \pm 0.1$ \\
\hline TGME49_203630 & Ribosomal protein RPL44 & $0.8 \pm 0.1$ \\
\hline
\end{tabular}

However, we were unable to identify the $\mathrm{C} 2 \mathrm{H} 2$ zinc finger motif $\mathrm{x}(2)$-Cys- $\mathrm{x}(2,4)$ Cys- $x(12)-H i s-x(3,5)-H i s ~[24]$ in the primary sequence of the deduced protein (Figure 8A). Homologs to the polypeptide encoded by ORF TGME49_319730 were identified in other apicomplexans, fungi and vertebrates. Alignments with the conserved hypothetical protein NCLIV_010410 from Neospora caninum (87\% identity), the protein FAM136A from Cyclospora cayetanensis (XP_022591373.1; 46\% identity), the conserved protein XP_001349642.1 from Plasmodium falciparum 3D7 (33\% identity), the protein FAM136A from Clupea harengus (XP_012669662.1; 25\% identity), and the human mitochondrial import inner membrane translocase subunit Tim10 (NP_036588.1; 12.5\% identity) are depicted in Figure 8B. To identify a possible function of this protein, a modeling was performed by comparing a potential structure to existing structures sharing similarities. In the Swiss Model repository, the template with the highest identity was $7 \mathrm{cgp} .1 .0$, the mitochondrial import membrane translocase subunit Tim10 encoded by NP_036588.1, which forms a 15-mer, as published in a recent cryo-EM study [25]. The model for ORF TgME49_319730 with a convenient QMEAN value (-0.47) is shown in Figure 8C. 


\section{MAFGSSSSSERYPSLEEGARSFQKKFEDMISSLTKRTLPLQRKAFECCVSCFDRHNDDHVKI ADCMTRCHQQGEAIMRSLQRETEVLQSKLDSCQKTCYTRFAQPDKSADPASFEAEREKCFTQ CFAEVEPFLSEVAQRVNRRIDEASQ}

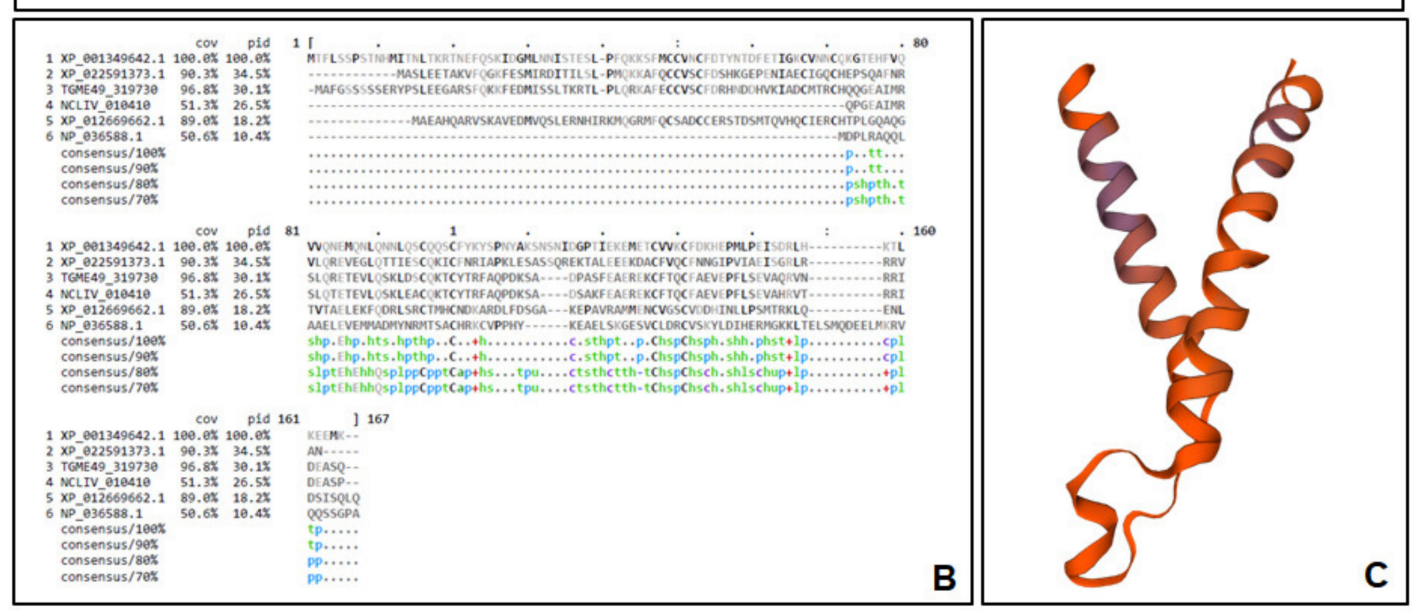

Figure 8. Deduced primary sequence of ORF TgME49_319730 is shown in (A). Alignments to five homologs and consensus sequences are presented in (B). Amino acid sequences are shown in grey, black amino acids indicate homologies or identities, from the consensus sequences, $\mathrm{s}, \mathrm{h}$ and $\mathrm{l}$ are indicated in green, $\mathrm{p}$ in blue, (C) Model structure calculated from the mitochondrial import membrane translocase subunit Tim10 encoded by NP_036588.1 with hydrophilic residues depicted in violet and hydrophobic residues in orange.

The second most abundant protein was TGME49_316710 encoding a hypothetical protein. Moreover, a class I fructose-1,6-bisphosphate aldolase [26] was amongst the most abundant compound 1-binding proteins (Table 2; see Table S3 for complete list).

The results obtained with the T. brucei pull-down were even sharper. Amongst the 48 proteins, which were specifically retained by compound 1, more than $64 \%$ were constituted by five mitochondrial ATP synthase subunits, the subunit encoded by ORF Tb927.5.3090 alone amounting to nearly 25\% of the specific compound 1-binding proteins (Table 3; see Table S4 for complete list).

Table 3. List of the 20 most abundant proteins from T. brucei TREU927 specifically binding to a complex 1 column, as identified by differential affinity chromatography followed by mass spectrometry. See Table S2 for the full dataset. The abundance is given as the percentage of the iBAQ values, with $100 \%$ being the sum of the iBAQ values of the 48 proteins specifically binding to 1 . Mean values \pm standard errors of three replicates are given.

\begin{tabular}{|c|c|c|}
\hline ORF Number & Annotation & $\begin{array}{c}\text { iBAQ } \\
\text { (\% of Total) }\end{array}$ \\
\hline Tb927.5.3090 & Mitochondrial ATP synthase subunit, putative & $24.9 \pm 4.6$ \\
\hline $\mathrm{Tb} 927.10 .5050$ & Mitochondrial ATP synthase epsilon chain & $20.0 \pm 4.2$ \\
\hline Tb927.5.2930 & Mitochondrial ATP synthase subunit, putative & $13.3 \pm 1.5$ \\
\hline Tb927.5.1160 & Degradation arginine-rich protein for mis-folding, putative & $4.1 \pm 0.6$ \\
\hline Tb927.11.600 & Mitochondrial ATP synthase subunit, putative & $3.4 \pm 0.5$ \\
\hline Tb927.3.3330 & Heat shock protein 20 , putative & $2.4 \pm 0.2$ \\
\hline Tb927.4.4910.1 & 3,2-trans-enoyl-CoA isomerase, mitochondrial precursor, putative & $2.3 \pm 0.3$ \\
\hline Tb927.3.2880 & Mitochondrial ATP synthase subunit, putative & $2.3 \pm 0.3$ \\
\hline Tb927.3.3750 & Paraflagellar rod component, putative & $2.0 \pm 0.0$ \\
\hline Tb927.10.13110 & Outer arm dynein light chain 7 & $2.0 \pm 0.6$ \\
\hline Tb927.10.4310 & Prohibitin 2, putative & $1.6 \pm 0.1$ \\
\hline
\end{tabular}


Table 3. Cont.

\begin{tabular}{|c|c|c|}
\hline ORF Number & Annotation & $\begin{array}{c}\text { iBAQ } \\
\text { (\% of Total) }\end{array}$ \\
\hline Tb927.4.3590 & Translation elongation factor 1-beta, putative & $1.6 \pm 0.3$ \\
\hline Tb927.7.2780 & Hypothetical protein, conserved & $1.5 \pm 0.7$ \\
\hline Tb927.6.4250 & Hypothetical protein, conserved & $1.4 \pm 0.2$ \\
\hline Tb927.9.4680 & Eukaryotic initiation factor $4 \mathrm{~A}-1$ & $1.4 \pm 0.1$ \\
\hline Tb927.6.3290 & Intraflagellar transport protein 20 & $1.2 \pm 0.3$ \\
\hline Tb927.8.4810 & Prohibitin 1 & $1.1 \pm 0.1$ \\
\hline Tb927.10.2080 & Hypothetical protein, conserved & $1.1 \pm 0.4$ \\
\hline Tb927.5.4500 & Ras-like small GTPase, putative & $1.0 \pm 0.1$ \\
\hline Tb927.3.5550 & Intraflagellar transport protein 27 & $1.0 \pm 0.2$ \\
\hline
\end{tabular}

In T. gondii, no mitochondrial, but vacuolar ATP-synthase subunits, which are homologs, were among the specific proteins binding to 1 . Furthermore, in both pulldowns, proteins involved in translation such as initiation and elongation factors and acyl-transferases were specifically eluted from compound 1 columns (Tables 1 and 2; Tables S3 and S4).

\subsection{Compound 1 Impairs the Stability of the T. brucei ATP-Synthase Complex}

The T. brucei ATP-synthase complex is composed of two subcomplexes, the membraneembedded $F_{o}$ and the soluble $F_{1}$, which are connected by a rotary central stalk and a stationary peripheral stalk [27]. The effect of drug treatment on the stability of the T. brucei ATP-synthase complex was investigated by exposing bloodstream forms to $50-400 \mathrm{nM}$ compound $\mathbf{1}$ or $\mathbf{2}$ for $1 \mathrm{~h}$, and extracts were separated by native PAGE (Figure 9A). Treatment with $200 \mathrm{nM}$ or $400 \mathrm{nM}$ compound 1 resulted in a significantly decreased amount of the ATP-synthase complex, while treatment with compound 2 had no effect (Figure 9B). In contrast, another mitochondrial complex, the ADP/ATP carrier protein (TbAAC), which is responsible for the exchange of free ADP and ATP across the inner mitochondrial membrane [28], was not affected by these treatments.

A

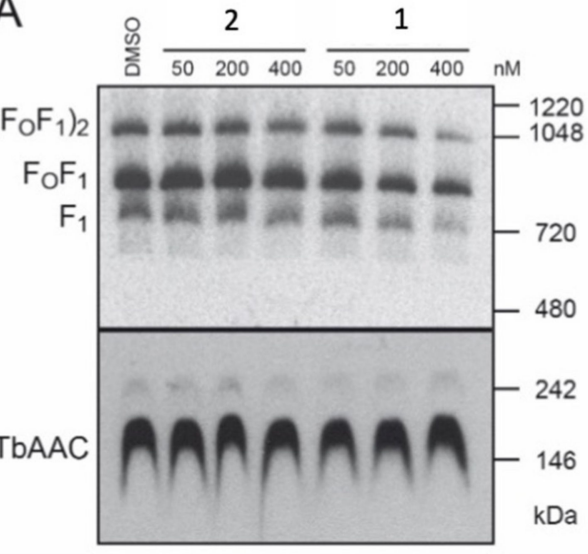

$\mathrm{B}$

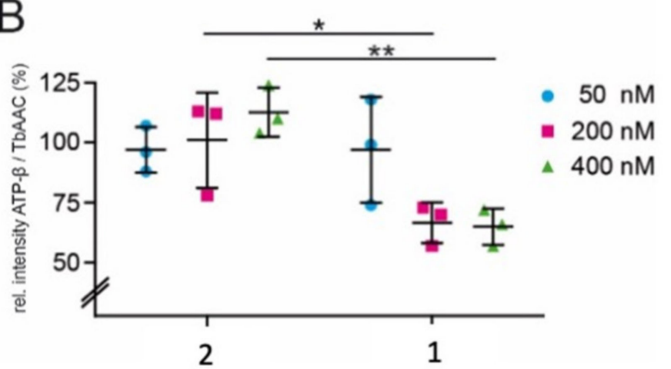

Figure 9. Native PAGE analysis and quantification of ATP-synthase complexes. (A) shows native PAGE and immunoblot analyses of mitochondria-enriched membranes after treatment with DMSO (mock control), or compound 1 or 2 for $1 \mathrm{~h}$. ATP synthase $F_{1}$ and $F_{o} F_{1}$ monomers and dimers $\left(\left(F_{0} F_{1}\right)_{2}\right)$ were visualized using the anti-ATP synthase subunit $\beta$ antibody (ATP- $\beta$ ), the loading control TbAAC was visualized with anti-TbAAC antibody. (B) shows protein quantification of samples from A analyzed by SDS-PAGE and immunoblotting. Ratios of signal intensities of ATP- $\beta$ versus TbAAC were compared to DMSO-treated samples ( $\mathrm{n} \geq 3) .{ }^{*} p<0.05,{ }^{* *} p<0.01$. 


\section{Discussion}

We here report on a trithiolato-bridged dinuclear $\mathrm{Ru}(\mathrm{II})$-arene compound $\mathbf{1}$ that is conjugated to a 9-(2-oxyethyl)-adenine unit, which is highly active against two evolutionary distinct protozoans, namely $T$. gondii belonging to the super-group Diaphoretickes (clade Alveolata) and T. brucei belonging to the group Euglenozoa of the super-group Excavata [1] Another di-ruthenium compound containing 2-thioxantine as one of the thiolato bridges 2 and 9-(2-hydroxyethyl)-adenine 3 displayed no in vitro activity against these two species. Thus, we were interested in the cellular and molecular targets in T. gondii and T. brucei with which compound 1 would specifically interact.

Cellular targets were investigated by TEM. In both parasites, compound $\mathbf{1}$ induced severe ultrastructural alterations most notably in the mitochondrion already $4-6 \mathrm{~h}$ after exposure to the drug, such as the swelling and dissolution of cristae and the mitochondrial matrix. In addition, in many instances, the matrix was replaced by membranous or filamentous material of unknown nature. In T. brucei, treatment with the drug also affected the structural integrity of the kinetoplast, which contains the mitochondrial DNA. While TEM suggested that other organelles were largely unaffected, it is important to note that the absence of ultrastructural evidence does not exclude the possibility that also other cellular entities might be affected by the drug.

These findings are in line with previous studies on a series of thiolato-bridged dinuclear ruthenium(II)-arene complexes that induced similar effects in both T. gondii and the closely related Neospora caninum [16,18], and also T. brucei bloodstream forms [19]. In the case of T. brucei, this type of compound also severely impaired the mitochondrial membrane potential.

When examining the overall pull-down results, it is striking that $\mathbf{1}$ has more common binding proteins with 2 than with its appended moiety 9-(2-oxyethyl)-adenine (3) (see Figure 1), which had only few binding proteins, most of them in common with the other compounds. This observation suggests a general high affinity of proteins to the cationic trithiolato di-ruthenium core structure of both compounds. It is worth noting also that both $\mathbf{1}$ and $\mathbf{2}$ contain a purine nucleobase in the structure. However, if in the case of $\mathbf{1}$ adenine is separated from the di-ruthenium unit by the presence of a short spacer, in 2, 2-thioxantine represents one of the bridges connecting the two ruthenium(II)-arene fragments. Then, these structural differences would trigger the specificity of the binding.

Only few proteins from both organisms binding to compound 1 columns are homologs, namely translation initiation and elongation factors and ribosomal proteins. This is in good agreement with previous findings obtained previously with another trithiolatobridged ruthenium-arene complex [14]. The translation machinery as a common target in both organisms is further evidenced when examining the protein-protein interaction network generated by the STRING knowledge base and software tool (Swiss Institute of Bioinformatics) for the compound 1-binding proteins from T. gondii (Figure S1) and T. brucei (Figure S2). However, protein networks show differences due to the different numbers of binding proteins identified in both organisms. Other proteins share common metabolic specifications such as nucleotide binding or transferase activities.

In both T. gondii and T. brucei, the most abundant proteins specifically binding to $\mathbf{1}$ are-in all likelihood-located to the mitochondrion. This is in a good agreement with the subcellular damage seen by TEM. In T. brucei, the observed destabilization of the major binding protein - the mitochondrial ATP synthase complex — would seriously affect mitochondrial integrity. In T. brucei, the role of the ATP synthase depends on the life cycle stage. In the insect/procyclic stage, the ATP synthase complex is responsible for producing ATP, while it consumes ATP in bloodstream form parasites. This switch is accompanied by changes in the mitochondrial ultrastructure. In addition to other functions, the mitochondrial ATP synthase is responsible for maintaining the mitochondrial membrane potential and preventing the intra-mitochondrial accumulation of ATP, since elevated ATP levels lead to inhibition of the alternative oxidase, the only terminal oxidase in bloodstream from parasites, and consequently to reduced respiration [29]. Since functional mitochondria are 
essential for the maintenance of cellular integrity [30], destabilization and inhibition of ATP synthase would explain the observed ultrastructural effects.

In the case of $T$. gondii, the situation is less clear. The function of the protein encoded by ORF TgME49_319730 is unknown. The homolog with the highest similarity of which a structural model exists, the human mitochondrial import inner membrane translocase subunit Tim10, is part of the mitochondrial translocase Tim22 complex [25]. This complex has a size of approximately $440 \mathrm{kDa}$ and consists of at least six different polypeptides, the protein Tim22 presumably forming a channel, and the Tim proteins 9, 10, and 29 and an acylglycerol kinase [31]. Mutations of proteins of this complex have been shown to impair protein import into mitochondria and lipid biosynthesis [32]. If the protein encoded by ORF TgME49_319730 is part of a similar complex in mitochondria of T. gondii, functional inhibition by drugs may result in a similar defect. This protein is certainly a candidate for further studies on mitochondria as a potential subcellular drug target.

\section{Materials and Methods}

\subsection{Culture Media, Biochemicals and Compounds}

Cell culture media was purchased from Gibco-BRL (Zürich, Switzerland), and biochemical agents were procured from Sigma, St. Louis, MO, USA). Compounds 1, 2, and 3 (see Figure 1) were synthesized as described in [Desiatkina et al., 2021, manuscript in prearation]. Compound $\mathbf{3}$ was purchased from TCI chemicals (Eschborn, Germany).

\subsection{In Vitro Culture of Parasites}

For electron microscopy, T. gondii ME49 tachyzoites were maintained and cultured in human foreskin fibroblasts as previously described [33]. For affinity chromatography necessitating high yields, tachyzoites were grown in Vero cells as previously described for Neospora caninum [34,35]. T. brucei TREU927 bloodstream forms were cultured as previously described [19]. The pellets of tachyzoites and bloodstream forms were stored at $-80^{\circ} \mathrm{C}$.

\subsection{In Vitro Proliferation/Viability Measurements}

Inhibition of $T$. gondii tachyzoite proliferation and $\mathrm{IC}_{50}$ determination were performed using a transgenic $T$. gondii $\mathrm{RH}$ strain constitutively expressing $\beta$-galactosidase ( $T$. gondii $\beta$-gal) as described for other trithiolato-bridged ruthenium-arene complexes $[15,16]$. Compounds were prepared as $1 \mathrm{mM}$ stock solutions in DMSO (dimethyl sulfoxide, Sigma, St. Louis, MO, USA). For activity assays, HFF monolayers were cultured in 96-well plates by seeding $5 \times 10^{3} \mathrm{HFF}$ per well and allowing them to grow to confluence in phenol-red-free culture medium at $37^{\circ} \mathrm{C} / 5 \% \mathrm{CO}_{2}$. For infection, $T$. gondii $\beta$-gal tachyzoites were separated from their host cells, parasites were isolated, and HFF monolayers were infected with freshly isolated tachyzoites $\left(1 \times 10^{3}\right.$ per well), with compounds solutions added concomitantly during infection at $0.007,0.01,0.03,0.06,0.12,0.25,0.5$, and $1 \mu \mathrm{M}$. After $72 \mathrm{~h}$ of culture, the medium was aspirated, and cells were permeabilized by adding $90 \mu \mathrm{L}$ PBS containing $0.05 \%$ Triton X-100. After the addition of $10 \mu \mathrm{L} 5 \mathrm{mM}$ chlorophenol red- $\beta$-Dgalactopyranoside (CPRG; Roche Diagnostics, Rotkreuz, Switzerland) dissolved in PBS, the absorption shift was measured at $570 \mathrm{~nm}$ wavelength at various time points using an EnSpire $^{\circledR}$ multimode plate reader (PerkinElmer, Inc., Waltham, MA, USA). The activity measured as the release of chlorophenol red over time was proportional to the number of live parasites down to 50 per well as determined in pilot assays. $\mathrm{IC}_{50}$ values were calculated after the logit-log-transformation of relative growth and subsequent regression analysis.

Screenings and $\mathrm{IC}_{50}$ calculations for T. brucei bloodstream forms were done as described previously [19] in 96-well flat-bottom plates, with each well containing $1.5 \times 10^{3}$ parasites in $100 \mu \mathrm{L}$ culture medium with or without a serial drug dilution. Ten 2-fold drug dilutions were used. After $72 \mathrm{~h}$ of compound exposure, $10 \mu \mathrm{L}$ AlamarBlue ${ }^{\circledR}$ (Resazurin; Sigma) was added to each well, allowing a color change via metabolic oxidation-reduction by viable trypanosomes during $2-3 \mathrm{~h}$. Subsequently, plates were read with a Flexsta- 
tion II microplate fluorimeter using an excitation wavelength of $536 \mathrm{~nm}$ and an emission wavelength of $588 \mathrm{~nm}$. IC 50 values were determined using the software GraphPad Prism 6.

Cytotoxicity assays using uninfected confluent HFF host cells were also performed by AlamarBlue assay. In brief, confluent HFF monolayers in 96-well plates were exposed to $0.1,1$, and $2.5 \mu \mathrm{M}$ of each compound. Non-treated HFF as well as DMSO controls $(0.01 \%$, $0.1 \%$, and $0.25 \%$ ) were included. After $72 \mathrm{~h}$ of incubation at $37{ }^{\circ} \mathrm{C} / 5 \% \mathrm{CO}_{2}$, the medium was removed, and plates were washed once with PBS. Resazurin stock solution was diluted 1:200 in PBS, and $200 \mu \mathrm{L}$ were added to each well. Plates were read at an excitation wavelength of $530 \mathrm{~nm}$ and emission wavelength of $590 \mathrm{nM}$ by the EnSpire ${ }^{\circledR}$ multimode plate reader (PerkinElmer, Inc.). Fluorescence was measured at different timepoints. Relative fluorescence units were calculated from timepoints with linear increase.

\subsection{Transmission Electron Microscopy}

Transmission electron microscopy (TEM) was performed as previously described [19,33,36]. In the case of T. gondii, confluent human foreskin fibroblasts grown in T25 flasks were infected with $10^{6} \mathrm{~T}$. gondii ME49 tachyzoites and maintained at $37^{\circ} \mathrm{C} / 5 \% \mathrm{CO}_{2}$ for $24 \mathrm{~h}$. Subsequently, treatment with $500 \mathrm{nM}$ of 1, 2, or 3, or solvent controls were initiated. After 6, 12, 24, 48, and $72 \mathrm{~h}$, the medium from the flasks was discarded; then, cells were washed in $0.1 \mathrm{M}$ sodium cacodylate buffer ( $\mathrm{pH} 7.3$ ) and fixed in $2 \%$ glutaraldehyde in cacodylate buffer for $10 \mathrm{~min}$ at room temperature. The fixed monolayers were gently scraped from the flasks, transferred into Eppendorf tubes, and fixed for $2 \mathrm{~h}$ at room temperature. T. brucei bloodstream forms grown in 24-well tissue culture devices were treated with $200 \mathrm{nM}$ of each compound in medium during $4 \mathrm{~h}$. Fixation was done by washing cells once in ice-cold $0.1 \mathrm{M}$ sodium cacodylate buffer, which was followed by fixation in $2 \%$ glutaraldehyde in cacodylate buffer for $2 \mathrm{~h}$ at room temperature. For both parasites, further preparation included post-fixation in $2 \%$ osmium tetroxide, pre-staining, stepwise dehydration in ethanol, and embedding in Epon-812 resin $[19,33,36]$. Following polymerization at $60^{\circ} \mathrm{C}$, ultrathin sections $(80 \mathrm{~nm})$ were cut using an ultramicrotome (Reichert and Jung, Vienna, Austria) and placed onto 200 mesh nickel grids (Plano GmbH, Marburg, Germany). Following staining, specimens were viewed on a Philips CM12 TEM operating at $80 \mathrm{kV}$.

\subsection{Protein Extraction and Affinity Chromatography}

For protein extraction, frozen pellets of T. gondii ME49 tachyzoites or T. brucei TREU927 bloodstream forms were resuspended in ice-cold extraction buffer, i.e., PBS (phosphatebuffered saline) containing 1\% Triton X-100 and 1\% of Halt proteinase inhibitor cocktail (ThermoFisher)). Suspensions were vortexed thoroughly and centrifuged (13,000 rpm, $10 \mathrm{~min}, 4^{\circ} \mathrm{C}$ ). Extraction of pellets was repeated twice. Three $\mathrm{mL}$ of extraction buffer was used in total. Supernatants were combined (resulting in approximately $3 \mathrm{mg}$ of total protein) and subjected to affinity chromatography.

To produce the sepharose matrices conjugated to compounds 1,2 , and 3, $0.5 \mathrm{~g}$ of lyophilized epoxy-sepharose with a C12 spacer was suspended in $15 \mathrm{~mL} \mathrm{H}_{2} \mathrm{O}$ and centrifuged at $300 \times g$ for $5 \mathrm{~min}$. Washes in water were repeated twice followed by a wash with coupling buffer (0.1 $\left.\mathrm{M} \mathrm{NaHCO}_{3}, \mathrm{pH} 9.5\right)$. After the last wash, $20 \mathrm{mg}$ of each compound dissolved in $2.5 \mathrm{~mL}$ DMSO (dimethylsulfoxide) were added, and coupling buffer was added to a maximum volume of $5 \mathrm{~mL}$. Mock column medium was generated by incubating $0.5 \mathrm{~g}$ of epoxy-sepharose with DMSO. The mixture was incubated for 3 days at $37^{\circ} \mathrm{C}$ under slow but continuous shaking to allow coupling of the epoxy group to the compounds. The resulting column medium (approximately $2 \mathrm{~mL}$ ) was washed with coupling buffer $(15 \mathrm{~mL})$ followed by a wash with ethanolamine (1 M, pH 9.5) and by an incubation in $10 \mathrm{~mL}$ of ethanolamine for $4 \mathrm{~h}$ at $20^{\circ} \mathrm{C}$ in the dark to block residual reactive groups. Then, the column medium was transferred to a chromatography column (Novagen, Merck, Darmstadt, Germany) and extensively washed with PBS-DMSO (1:1) and PBS to remove unbound compounds. The columns were stored in PBS containing $0.02 \% \mathrm{NaN}_{3}$ at $4{ }^{\circ} \mathrm{C}$. 
Prior to affinity chromatography, mock columns were combined to either 1 , 2, or 3 columns in tandem (mock first, then compound) and washed with $50 \mathrm{~mL}$ PBS equilibrated at $20{ }^{\circ} \mathrm{C}$. Crude extracts $(3 \mathrm{~mL})$ prepared as described above were loaded onto the columns with a flow rate of $0.25 \mathrm{~mL} / \mathrm{min}$. The column was washed with PBS until the baseline was flat (10 column volumes, corresponding to $25 \mathrm{~mL}$ ). Then, the columns were separated, and bound proteins were eluted with $50 \mathrm{mM}$ acetic acid ( $5 \mathrm{~mL}$ per column). The eluates were lyophilized and stored at $-80{ }^{\circ} \mathrm{C}$.

\subsection{Proteomic Analysis of the Eluted Proteins by Mass Spectrometry}

The lyophilized eluates were dissolved in $10 \mu \mathrm{L}$ of $8 \mathrm{M}$ urea and $0.1 \mathrm{M}$ of Tris- $\mathrm{HCl}^{-}$ ( $\mathrm{pH} 8$ ); then, $1 \mu \mathrm{L} 0.1 \mathrm{M}$ Tris- $\mathrm{Cl}^{-}(\mathrm{pH}$ 8) buffer containing $0.1 \mathrm{M}$ of dithiothreitol were added, which was followed by incubation for $30 \mathrm{~min}$ at $37{ }^{\circ} \mathrm{C}$ and constant mixing at $600 \mathrm{rpm}$. This step was repeated with $1 \mu \mathrm{L}$ of $0.5 \mathrm{M}$ of iodoacetamide. Iodoacetamide

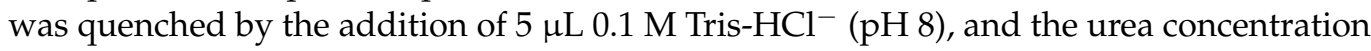
was further diluted to $4 \mathrm{M}$ by the addition of $2 \mathrm{mM}$ calcium dichloride in $20 \mathrm{mM}$ Tris buffer. Proteins were digested for $2 \mathrm{~h}$ at $37^{\circ} \mathrm{C}$ by the addition of $1 \mu \mathrm{L}$ of $0.1 \mu \mathrm{g} / \mu \mathrm{L}$ LysC sequencing grade protease (Promega), which was followed by further dilution of urea to 1.6 $\mathrm{M}$ with the above calcium dichloride buffer and $1 \mu \mathrm{L}$ of $0.1 \mu \mathrm{g} / \mu \mathrm{L}$ trypsin sequencing grade (Promega). Digestion was completed by incubation overnight at room temperature.

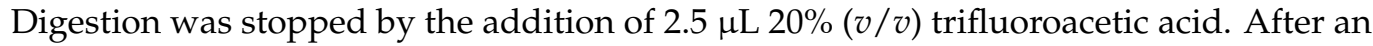
incubation for $15 \mathrm{~min}$ at room temperature, the digest was spun for $1 \mathrm{~min}$ at 16,000 $\mathrm{g}$, and the cleared supernatant was transferred to a HPLC vial for subsequent nano-liquid reversed phase chromatography coupled to tandem mass spectrometry, as described elsewhere [37].

The mass spectrometry data were processed with MaxQuant (v1.6.14.0) against a current protein sequence databases from toxodb.org (ToxoDB-47_TgondiiME49) and tritrypdb.org (TriTrypDB-50_TbruceiTREU927) [34]. Then, the MaxQuant search results were processed in R-studio using an in-house R script exactly as described before [34].

Modeling of the structure of a binding protein was performed using the Swiss Model homology modeling tools [38] of the Swiss Model repository [39]. Protein-protein interaction networks were generated using the STRING knowledge base and software tool (https:/ / string-db.org/; accessed on 12 February 2021).

\subsection{Crude Membrane Fractions and Native Polyacrylamide Gel Electrophoresis (PAGE)}

Crude mitochondrial membranes were obtained by digitonin extraction [40]. Briefly, $10^{7}$ trypanosomes were washed in TBS $(10 \mathrm{mM}$ Tris- $\mathrm{HCl} \mathrm{pH} \mathrm{7.5,} 144 \mathrm{mM} \mathrm{NaCl})$, suspended in $0.5 \mathrm{~mL}$ SoTE (20 mM Tris- $\mathrm{HCl}$, pH 7.5, 0.6 M sorbitol, 0.2 mM EDTA) followed by the addition of $0.5 \mathrm{~mL}$ SoTE containing $0.05 \%(w / v)$ digitonin. After $5 \mathrm{~min}$ on ice, crude membranes were collected by centrifugation $\left(6000 \times g, 5 \mathrm{~min}, 4^{\circ} \mathrm{C}\right)$. For native PAGE, crude membranes were solubilized in $20 \mu \mathrm{L}$ lysis buffer $(20 \mathrm{mM}$ Tris- $\mathrm{HCl}$, pH 7.2, $15 \mathrm{mM}$ $\mathrm{KH}_{2} \mathrm{PO}_{4}, 20 \mathrm{mM} \mathrm{MgSO}, 0.6 \mathrm{M}$ sorbitol, 1.5\% (w/v) digitonin), cleared, and supplemented with 10 times concentrated loading dye (100 mM Bis-Tris, $\mathrm{pH}$ 7, $500 \mathrm{mM}$ aminocaproic acid, $5 \%(w / v)$ Coomassie Blue G). Proteins were separated on 3-12\% NativePAGE gradient gels (Invitrogen Reinach, Switzerland) and transferred onto nitrocellulose membranes (Thermo Scientific, Waltham, MA, USA) using a semi-dry blotting system (BioRad, Cressier, Switzerland). Membranes were exposed to rabbit anti-ATP synthase subunit $\beta$ or rabbit anti-TbAAC (kindly provided by Alena Ziková, Biology Centre of the Czech Academy of Sciences), diluted 1:1000 in TBS containing 5\% (w/v) milk powder. Horseradish peroxidaseconjugated anti-rabbit (Dako, Glostrup, Denmark) was used at dilutions of 1:5000 and detected using an enhanced chemiluminescence detection kit (Thermo Scientific). Bands on blots were quantified using the gel analyzer function of Fiji [41].

Supplementary Materials: The following are available online at https://www.mdpi.com/article/10 .3390/ijms221910787/s1. 
Author Contributions: Conceptualization, J.M., J.F. and A.H.; Data curation, P.B., S.B.-L., M.H., J.F. and A.H.; Formal analysis, N.A., J.M. and A.H.; Funding acquisition, A.H.; Investigation, N.A., J.J., M.S., G.B., D.I., J.R., M.H., J.F. and A.H.; Methodology, N.A., J.M., J.J., M.S., G.B., D.I., J.R., O.D., E.P., S.B.-L. and A.H.; Project administration, J.F. and A.H.; Resources, J.F. and A.H.; Software, S.B.-L. and M.H.; Supervision, A.H.; Validation, J.J., P.B. and G.B.; Writing-original draft, J.M.; Writing-review and editing, N.A., J.M., J.J., M.S., P.B., G.B., D.I., J.R., O.D., E.P., S.B.-L., M.H., J.F. and A.H. All authors have read and agreed to the published version of the manuscript."

Funding: This research was funded by Swiss National Science Foundation, grant number 310030_184662 and CRSII5_173718, and the APC was funded by the Swiss National Science Foundation.

Institutional Review Board Statement: Not applicable.

Informed Consent Statement: Not applicable.

Data Availability Statement: Data are made available as supplementary datasets (see above).

Acknowledgments: We thankfully acknowledge David Sibley, Washington University of St. Louis, for providing the T. gondii- $\beta$-gal strain used in this study. Many thanks to Vreni Balmer, Institute of Parasitology, for excellent technical support.

Conflicts of Interest: The authors declare no conflict of interest.

\section{References}

1. Adl, S.M.; Simpson, A.G.; Lane, C.E.; Lukes, J.; Bass, D.; Bowser, S.S.; Brown, M.W.; Burki, F.; Dunthorn, M.; Hampl, V.; et al. The revised classification of eukaryotes. J. Eukaryot Microbiol. 2012, 59, 429-493. [CrossRef] [PubMed]

2. Matta, S.K.; Rinkenberger, N.; Dunay, I.R.; Sibley, L.D. Toxoplasma gondii infection and its implications within the central nervous system. Nat. Rev. Microbiol. 2021, 19, 467-480. [CrossRef]

3. Hampton, M.M. Congenital toxoplasmosis: A review. Neonatal Netw. 2015, 34, 274-278. [CrossRef] [PubMed]

4. Dunay, I.R.; Gajurel, K.; Dhakal, R.; Liesenfeld, O.; Montoya, J.G. Treatment of toxoplasmosis: Historical perspective, animal models, and current clinical practice. Clin. Microbiol. Rev. 2018, 31, e00057-17. [CrossRef]

5. Franco, J.R.; Simarro, P.P.; Diarra, A.; Ruiz-Postigo, J.A.; Jannin, J.G. The journey towards elimination of gambiense human African trypanosomiasis: Not far, nor easy. Parasitology 2014, 141, 748-760. [CrossRef] [PubMed]

6. Giordani, F.; Morrison, L.J.; Rowan, T.G.; HP, D.E.K.; Barrett, M.P. The animal trypanosomiases and their chemotherapy: A review. Parasitology 2016, 143, 1862-1889. [CrossRef] [PubMed]

7. Buscher, P.; Cecchi, G.; Jamonneau, V.; Priotto, G. Human African trypanosomiasis. Lancet 2017, 390, 2397-2409. [CrossRef]

8. Dubey, J.P. Toxoplasmosis of Animals and Humans, 2nd ed.; CRC Press: Boca Raton, NJ, USA, 2010; pp. 313-314.

9. Attias, M.; Teixeira, D.E.; Benchimol, M.; Vommaro, R.C.; Crepaldi, P.H.; De Souza, W. The life-cycle of Toxoplasma gondii reviewed using animations. Parasites Vectors 2020, 13, 588. [CrossRef]

10. Romero-Meza, G.; Mugnier, M.R. Trypanosoma brucei. Trends Parasitol. 2020, 36, 571-572. [CrossRef]

11. Matthews, K.R. The developmental cell biology of Trypanosoma brucei. J. Cell Sci. 2005, 118, 283-290. [CrossRef]

12. Lujan, H.D. Trying to get rid of protozoan parasites. Curr. Opin. Microbiol. 2012, 15, 447-448. [CrossRef]

13. Müller, J.; Hemphill, A. New approaches for the identification of drug targets in protozoan parasites. Int. Rev. Cell Mol. Biol 2013, 301, 359-401. [CrossRef] [PubMed]

14. Basto, A.P.; Müller, J.; Rubbiani, R.; Stibal, D.; Giannini, F.; Suss-Fink, G.; Balmer, V.; Hemphill, A.; Gasser, G.; Furrer, J. Characterization of the activities of dinuclear thiolato-bridged arene ruthenium complexes against Toxoplasma gondii. Antimicrob. Agents Chemother. 2017, 61, e01031-17. [CrossRef] [PubMed]

15. Studer, V.; Anghel, N.; Desiatkina, O.; Felder, T.; Boubaker, G.; Amdouni, Y.; Ramseier, J.; Hungerbuhler, M.; Kempf, C.; Heverhagen, J.T.; et al. Conjugates containing two and three trithiolato-bridged dinuclear ruthenium(II)-arene units as in vitro antiparasitic and anticancer agents. Pharmaceuticals 2020, 13, 471. [CrossRef] [PubMed]

16. Desiatkina, O.; Paunescu, E.; Mosching, M.; Anghel, N.; Boubaker, G.; Amdouni, Y.; Hemphill, A.; Furrer, J. Coumarin-tagged dinuclear trithiolato-bridged ruthenium(II)arene complexes: Photophysical properties and antiparasitic activity. Chembiochem 2020, 21, 2818-2835. [CrossRef] [PubMed]

17. Barna, F.; Debache, K.; Vock, C.A.; Kuster, T.; Hemphill, A. In vitro effects of novel ruthenium complexes in Neospora caninum and Toxoplasma gondii tachyzoites. Antimicrob. Agents Chemother. 2013, 57, 5747-5754. [CrossRef]

18. Basto, A.P.; Anghel, N.; Rubbiani, R.; Müller, J.; Stibal, D.; Giannini, F.; Suss-Fink, G.; Balmer, V.; Gasser, G.; Furrer, J.; et al. Targeting of the mitochondrion by dinuclear thiolato-bridged arene ruthenium complexes in cancer cells and in the apicomplexan parasite Neospora caninum. Metallomics 2019, 11, 462-474. [CrossRef]

19. Jelk, J.; Balmer, V.; Stibal, D.; Giannini, F.; Suss-Fink, G.; Butikofer, P.; Furrer, J.; Hemphill, A. Anti-parasitic dinuclear thiolatobridged arene ruthenium complexes alter the mitochondrial ultrastructure and membrane potential in Trypanosoma brucei bloodstream forms. Exp. Parasitol. 2019, 205, 107753. [CrossRef] 
20. Fernandez, M.; Arce, E.R.; Sarniguet, C.; Morais, T.S.; Tomaz, A.I.; Azar, C.O.; Figueroa, R.; Diego Maya, J.; Medeiros, A.; Comini, M.; et al. Novel ruthenium(II) cyclopentadienyl thiosemicarbazone compounds with antiproliferative activity on pathogenic trypanosomatid parasites. J. Inorg. Biochem. 2015, 153, 306-314. [CrossRef]

21. Gazanion, E.; Vergnes, B. Protozoan Parasite Auxotrophies and Metabolic Dependencies. Exp. Suppl. 2018, 109, 351-375. [CrossRef]

22. Coppens, I. Exploitation of auxotrophies and metabolic defects in Toxoplasma as therapeutic approaches. Int. J. Parasitol. 2014, 44, 109-120. [CrossRef] [PubMed]

23. Kokina, A.; Ozolina, Z.; Liepins, J. Purine auxotrophy: Possible applications beyond genetic marker. Yeast 2019, 36, 649-656. [CrossRef] [PubMed]

24. Iuchi, S. Three classes of C2H2 zinc finger proteins. Cell Mol. Life Sci. 2001, 58, 625-635. [CrossRef] [PubMed]

25. Qi, L.; Wang, Q.; Guan, Z.; Wu, Y.; Shen, C.; Hong, S.; Cao, J.; Zhang, X.; Yan, C.; Yin, P. Cryo-EM structure of the human mitochondrial translocase TIM22 complex. Cell Res. 2021, 31, 369-372. [CrossRef]

26. Heron, P.W.; Sygusch, J. Isomer activation controls stereospecificity of class I fructose-1,6-bisphosphate aldolases. J. Biol. Chem. 2017, 292, 19849-19860. [CrossRef]

27. Gahura, O.; Hierro-Yap, C.; Zikova, A. Redesigned and reversed: Architectural and functional oddities of the trypanosomal ATP synthase. Parasitology 2021, 148, 1151-1160. [CrossRef] [PubMed]

28. Ruprecht, J.J.; King, M.S.; Zogg, T.; Aleksandrova, A.A.; Pardon, E.; Crichton, P.G.; Steyaert, J.; Kunji, E.R.S. The molecular mechanism of transport by the mitochondrial ADP/ATP carrier. Cell 2019, 176, 435-447.e15. [CrossRef]

29. Luevano-Martinez, L.A.; Girard, R.; Alencar, M.B.; Silber, A.M. ATP regulates the activity of an alternative oxidase in Trypanosoma brucei. FEBS Lett. 2020, 594, 2150-2158. [CrossRef] [PubMed]

30. Verner, Z.; Basu, S.; Benz, C.; Dixit, S.; Dobakova, E.; Faktorova, D.; Hashimi, H.; Horakova, E.; Huang, Z.; Paris, Z.; et al. Malleable mitochondrion of Trypanosoma brucei. Int. Rev. Cell Mol. Biol. 2015, 315, 73-151. [CrossRef]

31. Kang, Y.; Fielden, L.F.; Stojanovski, D. Mitochondrial protein transport in health and disease. Semin. Cell Dev. Biol 2018, 76, 142-153. [CrossRef]

32. Pfanner, N.; Warscheid, B.; Wiedemann, N. Mitochondrial proteins: From biogenesis to functional networks. Nat. Rev. Mol. Cell Biol. 2019, 20, 267-284. [CrossRef] [PubMed]

33. Winzer, P.; Müller, J.; Aguado-Martinez, A.; Rahman, M.; Balmer, V.; Manser, V.; Ortega-Mora, L.M.; Ojo, K.K.; Fan, E.; Maly, D.J.; et al. In vitro and in vivo effects of the bumped kinase inhibitor 1294 in the related cyst-forming apicomplexans Toxoplasma gondii and Neospora caninum. Antimicrob. Agents Chemother. 2015, 59, 6361-6374. [CrossRef] [PubMed]

34. Srinivasan, S.; Müller, J.; Suana, A.; Hemphill, A. Vaccination with microneme protein NcMIC4 increases mortality in mice inoculated with Neospora caninum. J. Parasitol. 2007, 93, 1046-1055. [CrossRef]

35. Müller, J.; Hemphill, A. Identification of a host cell target for the thiazolide class of broad-spectrum anti-parasitic drugs. Exp. Parasitol. 2011, 128, 145-150. [CrossRef]

36. Anghel, N.; Balmer, V.; Müller, J.; Winzer, P.; Aguado-Martinez, A.; Roozbehani, M.; Pou, S.; Nilsen, A.; Riscoe, M.; Doggett, J.S.; et al. Endochin-like quinolones exhibit promising efficacy against Neospora caninum in vitro and in experimentally infected pregnant mice. Front. Vet. Sci 2018, 5, 285. [CrossRef]

37. Müller, J.; Heller, M.; Uldry, A.C.; Braga, S.; Müller, N. Nitroreductase activites in Giardia lamblia: ORF 17150 encodes a quinone reductase with nitroreductase activity. Pathogens 2021, 10, 129. [CrossRef] [PubMed]

38. Waterhouse, A.; Bertoni, M.; Bienert, S.; Studer, G.; Tauriello, G.; Gumienny, R.; Heer, F.T.; de Beer, T.A.P.; Rempfer, C.; Bordoli, L.; et al. SWISS-MODEL: Homology modelling of protein structures and complexes. Nucleic Acids Res. 2018, 46, W296-W303. [CrossRef]

39. Bienert, S.; Waterhouse, A.; de Beer, T.A.; Tauriello, G.; Studer, G.; Bordoli, L.; Schwede, T. The SWISS-MODEL Repository-new features and functionality. Nucleic Acids Res. 2017, 45, D313-D319. [CrossRef] [PubMed]

40. Charrière, F.; Helgadottir, S.; Horn, E.K.; Soll, D.; Schneider, A. Dual targeting of a single tRNA(Trp) requires two different tryptophanyl-tRNA synthetases in Trypanosoma brucei. Proc. Natl. Acad. Sci. USA 2006, 103, 6847-6852. [CrossRef]

41. Schindelin, J.; Arganda-Carreras, I.; Frise, E.; Kaynig, V.; Longair, M.; Pietzsch, T.; Preibisch, S.; Rueden, C.; Saalfeld, S.; Schmid, B.; et al. Fiji: An open-source platform for biological-image analysis. Nat. Methods 2012, 9, 676-682. [CrossRef] 